\title{
GENETIC RESEARCH OF QUANTITATIVE TRAITS OF INBRED LINES OF WINTER RYE (Secale cereale L.) IN DIALLEL CROSSINGS
}

\section{A.A. GONCHARENKO, S.V. KRAHMALEV, A.V. MAKAROV, S.A. YERMAKOV}

«Nemchinovka» Moscow Research Institute for Agriculture, Russian Academy of Agricultural Sciences, gp Novoivanovskoe, Odintsovo Region, Moscow Province, 143026 Russia, e-mail goncharenko05@mail.ru Received March 5, 2013

\section{Abstract}

One of effective methods for estimation of inbred lines of winter rye is the diallel analysis allowing to spread out genotypic variance to general (GCA) and specific (SCA) combinational abilities and to estimate quantitatively the contribution of the basic gene interactions in expression of traits. The purpose of our research was studying genetic features of inbred lines of rye by means of diallel crossings. Tested 5 inbred lines of winter rye and 10 interline $F_{1}$ hybrids were obtained according to incomplete diallel scheme (B. Griffing, 1956). Parental lines and $F_{1}$ hybrids were compared in 2011 and 2012 in a field experiments under the scheme of a Latin square $(6 \times 3 \times 3)$ on the plots of $8.8 \mathrm{~m}^{2}$ in 3 replicates at a sowing rate of 500 seeds per $1 \mathrm{~m}^{2}$. Comparative estimation of gene effects has been carried out for 17 traits. The genetic parameters D, H1, H2, $\sqrt{ } \mathrm{H} 1 / \mathrm{D}$, $\mathrm{H} 2 / 4 \mathrm{H} 1$ and $\mathrm{h}^{2}$ according to B.I. Hayman (1954) were evaluated, and also the contribution of GCA and SCA effects into genotypic variance was assessed. It was shown that according to effects of GCA to SCA ratio the traits can be divided into two groups. The first group contained 5 traits with low heritability $\left(\mathrm{h}^{2}=0.10-0.22\right)$, exactly the productivity, number of productive stalks per $1 \mathrm{~m}^{2}$, number of grains in an ear, height of plant and the content of starch. In this group the contribution of GCA effects was rather low and varied from 7.0 up to $36.4 \%$, and the expression of traits strongly depended on domination and epistasis. In the second group there were 12 traits with rather high heritability $\left(h^{2}=0.28-0.62\right)$ for which an additive dispersion exceeded the component of domination and varied from 50.3 up to $82.0 \%$. These high-hereditable traits were the winter hardiness, weight of 1000 grains, a grain unit, number of falling, amylogramm peak, viscosity of water extract, temperature of pasting starch, fluidity of dough, loaf volume, the content of protein in grain, sensitivity to snow mould and brown rust. For six traits of this group a strong genotype-environment interaction was characteristic. The conclusion is made that cumulative accumulation of valuable genes by means of recurrent selection is advisable for improvement of inbred lines on these traits in the course of breeding.

Keywords: winter rye, inbred lines, quantitative traits, diallel analysis, general and specific combinational ability, genetic parameters.

One of top-priority areas in winter rye breeding is the use of a heterosis effect and obtaining of $F_{1}$ hybrids based on Cytoplasmic Male Sterility (CMS) [1]. Now, the rye hybrids created in Germany occupy about $70 \%$ of the total area under this crop and have put a significant pressure on population varieties in most of the Central European countries where the rye is cultivated. H.H. Geiger and T. Miedaner [2] report that, from 1982 to 2005, annual average increase in yield due to breeding of hybrid and population varieties was 51 and $30 \mathrm{~kg}$, respectively. In addition, the superiority of hybrids over population varieties is evident not only in yielding capacity, but also in shorter stem length, better lodging resistance, higher grain quality, etc. [3].

For efficient selection of inbred lines of the winter rye, it is very important to know what kinds of gene interactions are involved in provision of hereditary polymorphism of characters, what the nature of their expression is, in what correlation relationship they are, what the share of contribution from specific genetic effects (in particular, additive, dominant and various epistatic effects) is, and in what extent such effects are modified by environmental factors. In order to solve this problem, diallelic analysis is widely used in breeding. It allows us to 
break the genotypic variance of the character down into components - General Combining Ability (GCA) and Specific Combining Ability (SCA), and quantitatively estimate the contribution of some or other gene interactions to character expression.

Virtually all selected characters of the rye are polygenic by nature, and their phenotypic manifestation is a sum of the effects of allelic and nonallelic interaction in respect to many genes (such effects are significantly corrected by environmental conditions). The heterosis effect with regard to selected characters in the system of diallelic crossings of inbred rye lines is poorly known yet. It is reported for the majority of characters that the GCA variance is significantly higher than the SCA variance. H.H. Geiger [4] presents the summary of GCA variance shares for a number of crops; it follows from these data that this value for the rye is equal to $21 \%$, which is $2.0-2.5$ times less than the corresponding value for the corn and sugar beet. Therefore, the assessment of winter rye lines by GCA is considered to be more important than by SCA, and in practice, SCA effects are taken into account only at the final stage of experimental hybrid investigation [2].

It has been noted [5] that phenotypic expression of many characters for inbred lines per se may serve as a ground for prediction of their GCA. Therefore, it is proposed to actively select selfed lines for their own high productivity and repeatedly test them for GCA [1]. However, significant correlation between the productivity of inbred lines and the productivity of their hybrids shows itself for not all of characters. The reason is that they have different degrees of heritability. It is highly heritable characters that lead to noticeable genetic shift in case of indirect selection of lines in the process of breeding [6]. If dominance effects prevail in genetic control of a character, selection shall be based not on line productivity per se, but on the productivity of $F_{1}$ interline hybrids [7].

Researchers do not fully understand a genetic determination mechanism for the yielding capacity character and associated structural components. The same can be said about rye grain quality characters. Quite controversial conclusions have been drawn with regard to the structure of the heritable variance of the selected characters and share of contribution from specific genetic effects, in particular, additive, dominance and epistatic ones. H.H. Geiger [5] has determined that, for most of winter rye characters, the additive variance is much greater than the sum of all other components of the genetic variance. It is believed that, even in case of grain yield, nonadditive effects contribute to the genetic variance less than additive ones, although some hybrids obtained by crossing of high-GCA lines may be characterized by significant dominance effect. Lines may vary in adaptiveness to cultivation conditions and have a substantial influence on the variance of genotype-environment interaction. Other researchers also note the predominant contribution of the additive variance $[6,8,9]$.

The significant part of nonadditive variance of the rye is accounted for the epistatic interaction of genes [10]. Depending on a genotype and environmental conditions, this component of the genotypic variance may significantly increase or reduce the character value. In the latter case, the breeder has to seek ways to minimize negative consequences of nonallelic interaction so that to use SCA effects to the maximum extent possible [11].

Our task was to investigate the combining ability of inbred lines of the winter rye in the system of diallelic crossings and comparatively assess basic kinds of the gene interactions affecting the value of important breeding characters.

Technique. The parent material was represented by 5 inbred lines of the winter rye (H-649, H-1078, H-1179, H-451, H-842) and $10 \mathrm{~F}_{1}$ interline hybrids obtained in accordance with an incomplete diallelic pattern (Method II accord- 
ing to B. Griffing) [12]. The studied lines were consecutively subjected to repeated inbreeding $\left(\mathrm{S}_{14}-\mathrm{S}_{16}\right)$ and were deeply homozygous. The lines were crossed under the conditions of the Moscow Region in 2010 in $25 \mathrm{~m}^{2}$ isolating houses where the CMS analogs of above-listed lines were seeded near fertile forms for cross pollination. Parent lines and $F_{1}$ interline hybrids were studied in a field trial established in 2011-2012 based on a Latin rectangle design $(6 \times 3 \times 3)$ on 8 row plots with the area of $8.8 \mathrm{~m}^{2}$, in three replicates, at the seeding rate of 500 grains per $1 \mathrm{~m}^{2}$.

The following parameters were taken into account for each plot: yielding capacity (t/ha), winter hardiness, number of productive stems per $1 \mathrm{~m}^{2}$, number of grains per spike, plant height, weight of 1,000 grains, grain unit, falling number, amylogram height, aqueous extract viscosity, starch gelatinization temperature, dough shape stability (H/D), pan bread volume, protein and starch content in grain, and resistance to damage by the snow mold and brown rust. The general and specific combining abilities of lines were determined according to B. Griffing [12], and the genetic analysis of the diallelic complex was performed according to B.I. Hayman [13]: genetic parameters D, $\mathrm{H}_{1}, \mathrm{H}_{2},{ } \mathrm{H}_{1} / \mathrm{D}, \mathrm{H}_{2} / 4 \mathrm{H}_{1}$ and $\mathrm{h}^{2}$ were determined, and the share of contribution from GCA and SCA effects to the genotypic variance of the character was calculated.

Statistical data processing was carried out using the Agros software program (2.13).

Results. The field trial was carried out in the years with different weather conditions. Hot and dry weather was predominant in June and July 2011. It accelerated the phases of earing, blossom and grain filling; no grain lodging was observed; harvesting occurred 10 days earlier than the date according to longterm observations. In 2012, plants overwintered well, and the density of the formed stand was high, but abundant precipitation in June (150\% of mean annual value) led to early (in the blossom phase) crop lodging, which had a negative impact on yield and grain quality.

Statistical processing of initial data has revealed significant differences between the parent lines and hybrids with regard to all the characters studied. The analysis of variance of the combining ability has shown that significant contribution to the heritable variance of characters was both from GCA and SCA. However, the share of these components greatly varied depending on a character.

Taking a relative contribution of GCA and SCA to the genotypic variance as a basis, we have divided all the characters studied into two groups. The first group included 5 characters with low $\left(\mathrm{h}^{2}=0.10-0.22\right)$ heritability (yielding capacity, number of productive stems per $1 \mathrm{~m}^{2}$, number of grains per spike, plant height and starch content), for which the contribution from effects of GCA was lower than from those of SCA (average contribution varied within $7.0-36.4 \%$ in the years of the studies). The second group comprised 12 characters with relatively high heritability $\left(\mathrm{h}^{2}=0.28-0.62\right)$, for which the additive variance component exceeded the dominance component and varied from 50.3 to $82.0 \%$. These characters were winter hardiness, weight of 1,000 grains, grain unit, falling number, amylogram height, aqueous extract viscosity, starch gelatinization temperature, hearth bread shape stability, pan bread volume, protein content in grain, and damage by the snow mold and brown rust (Table 1).

1. The groups of quantitative characters by the value of contribution from general and specific combining abilities to their genotypic variance for the winter rye (Secale cereale L.) by observation years (Moscow Region)

\begin{tabular}{lc|c|c}
\hline \multicolumn{1}{c}{ Character } & 2011 & 2012 & Average \\
\hline & G r o u p 1 (GCA $<$ SCA) \\
Yielding capacity & $4.4 / 94.5$ & $9.5 / 87.9$ & $7.0 / 91.2$ \\
Number of productive stems per $1 \mathrm{~m}^{2}$ & $43.9 / 56.1$ & $20.6 / 68.4$ & $32.3 / 62.3$
\end{tabular}


Number of grains per spike

Plant height

Starch content

Winter hardiness

Weight of 1,000 grains

Aqueous extract viscosity

Falling number

Amylogram height

Starch gelatinization temperature

Grain unit

Dough shape stability

Volume yield of bread

Protein content

Snow mold resistance

Brown rust resistance

variance are shown before and after the slash, respectively.

The GCA of parent forms may be indicative of their breeding value.

The lines studied in our experiments had both positive and negative estimates of GCA effects (Table 2). With regard to yielding capacity and some other characters, relatively high GCA was noted for lines H-649, H-1179 and H-451. In breeding programs, they may be valuable components for synthesis of highyielding hybrids with high quality of grain. The differentiation between the lines allows us to conclude that each of them contains a specific complex of genes having a different impact on the combining ability. Strong contrast between inbred lines and $F_{1}$ hybrids with regard to yielding capacity additionally confirms that the genetic variance of this character is primarily determined by intralocus dominance and nonallelic interaction of genes.

2. The effects of general combining ability $\left(g_{i}\right)$ for winter rye (Secale cereale L.) inbred lines by groups of quantitative characters (Moscow Region, average for 2011-2012)

\begin{tabular}{|c|c|c|c|c|c|c|}
\hline Character & H-649 & $\mathrm{H}-1078$ & $\mathrm{H}-1179$ & $\mathrm{H}-451$ & H-842 & $r$ \\
\hline \multicolumn{7}{|c|}{ Group $1(\mathrm{GCA}<\mathrm{SCA})$} \\
\hline Yielding capacity: & & & & & & \multirow{3}{*}{$0.10-0.55$} \\
\hline centners/ha & 22.9 & 21.0 & 34.5 & 28.7 & 28.9 & \\
\hline $\mathrm{g}_{\mathrm{i}}$ & 4.6 & -0.8 & 2.1 & -1.9 & -4.0 & \\
\hline \multicolumn{7}{|c|}{ Number of productive stems per $1 \mathrm{~m}^{2}$ : } \\
\hline pes & 287 & 362 & 443 & 399 & 512 & \multirow[t]{2}{*}{$0.73-0.79$} \\
\hline $\mathrm{g}_{\mathrm{i}}$ & -33.0 & 13.4 & 38.5 & -31.6 & 12.8 & \\
\hline \multicolumn{7}{|l|}{ Number of grains per spike: } \\
\hline pcs & 30.3 & 35.4 & 29.9 & 37.6 & 34.2 & \multirow[t]{2}{*}{$0.74-0.78$} \\
\hline $\mathrm{g}_{\mathrm{i}}$ & 0.3 & -0.6 & -3.4 & 2.3 & 1.4 & \\
\hline \multicolumn{7}{|l|}{ Plant height: } \\
\hline $\mathrm{cm}$ & 91.7 & 89.0 & 117.5 & 90.7 & 94.2 & \multirow[t]{2}{*}{$0.91-0.98^{*}$} \\
\hline $\mathrm{g}_{\mathrm{i}}$ & -0.88 & -4.3 & 6.5 & -0.65 & -0.72 & \\
\hline \multicolumn{7}{|l|}{ Starch content: } \\
\hline$\%$ & 56.7 & 57.2 & 55.5 & 57.4 & 56.4 & \multirow[t]{2}{*}{$0.89-0.95^{*}$} \\
\hline \multirow[t]{2}{*}{$\mathrm{g}_{\mathrm{i}}$} & 0.28 & 0.15 & -0.67 & 0.59 & -0.35 & \\
\hline & \multicolumn{3}{|c|}{ Group 2 (GCA > SCA) } & & & \\
\hline Winter hardiness: & & & & & & \multirow{3}{*}{$0.95-0.98^{*}$} \\
\hline$\%$ & 90.6 & 77.9 & 94.8 & 73.5 & 94.3 & \\
\hline $\mathrm{g}_{\mathrm{i}}$ & 0.9 & -3.4 & 4.6 & -5.4 & 3.4 & \\
\hline \multicolumn{7}{|l|}{ Weight of 1,000 grains: } \\
\hline $\mathrm{g}$ & 26.6 & 16.8 & 26.2 & 19.2 & 16.8 & \multirow[t]{2}{*}{$0.96-0.99^{*}$} \\
\hline $\mathrm{g}_{\mathrm{i}}$ & 2.4 & -1.8 & 1.7 & -0.3 & -2.0 & \\
\hline \multicolumn{7}{|l|}{ Aqueous extract viscosity: } \\
\hline $\mathrm{cP}$ & 8.0 & 5.5 & 7.1 & 3.4 & 3.9 & \multirow[t]{2}{*}{$0.98-0.99^{*}$} \\
\hline $\mathrm{g}_{\mathrm{i}}$ & 1.19 & -0.18 & 0.82 & -1.03 & -0.86 & \\
\hline \multicolumn{7}{|l|}{ Falling number: } \\
\hline $\mathrm{s}$ & 103 & 174 & 235 & 313 & 161 & \multirow[t]{2}{*}{$0.95-0.99^{*}$} \\
\hline $\mathrm{g}_{\mathrm{i}}$ & -24.4 & -12.5 & 9.1 & 41.8 & -14.1 & \\
\hline \multicolumn{7}{|l|}{ Amylogram height: } \\
\hline amylograph units & 169 & 132 & 224 & 594 & 114 & \multirow[t]{2}{*}{$0.91-0.98^{*}$} \\
\hline $\mathrm{g}_{\mathrm{i}}$ & 5.2 & -83.3 & -9.2 & 137.1 & -49.8 & \\
\hline
\end{tabular}


An important criterion is the value of the coefficient of correlation $(r)$ between the quantitative aspect of the character of homozygous lines per se and GCA effects. In our experiments, it was highly significant for all the characters studied except for yielding capacity, number of productive stems per $1 \mathrm{~m}^{2}$ and number of grains per spike (see Table 2). This creates difficulties for breeding because early prediction of GCA using these characters is impossible for inbred lines, and intensive testing of $F_{1}$ hybrids derived on their basis is required. The reason is that the correlation between own productivity of lines and their advantage in crossings depends on which part of the variance is determined by additive genes [14]. In our experiments, the share of GCA contribution to the yielding capacity character variance turned out to be low (7.0\% on average). Therefore, when this character is used as an indirect criterion for selection, the probability of obtaining highly heterotic hybrids based on lines with the best yielding capacity will be low. In this respect, the rye is similar to the corn, for which the productivity of lines per se is also not a reliable indicator of their GCA [15]. However, the high yielding capacity of inbred lines should not be neglected because it is important for their seed breeding.

The analysis of genetic variability parameters has shown (Table 3) that the potential of rye productivity and grain quality characters depends on the effects exerted by three types of gene interactions: additive interaction (when effects are summarized for multiple loci), dominance (intralocus interaction of genes) and epistasis (nonallelic interaction of genes). However, their share of contribution to the character variance greatly varied by years and was a function of close interaction of the tested genotypes with the limiting environmental factors (precipitation, lodging) that altered the spectrum of the efficient genes determining the average value and genotypic variance of characters.

3. The comparative assessment of genetic variability parameters of quantitative characters with different ratios between general and specific combining abilities of the winter rye (Secale cereale L.) by observation years (Moscow Region)

\begin{tabular}{|c|c|c|c|c|c|c|}
\hline \multirow{2}{*}{ Character } & \multirow{2}{*}{$\begin{array}{l}\mathrm{GCA} / \mathrm{SCA} \\
\text { ratio }\end{array}$} & \multicolumn{5}{|c|}{ Genetic parameters } \\
\hline & & $\mathrm{D}$ & $\mathrm{H}_{1}$ & $\mathrm{H}_{1} / \mathrm{D}$ & $\mathrm{H}_{2} / 4 \mathrm{H}_{1}$ & $\mathrm{~h}^{2}$ \\
\hline \multicolumn{7}{|c|}{2011} \\
\hline Yielding capacity & 0.1 & 9.3 & $2,268^{*}$ & 15.6 & 0.247 & 0.10 \\
\hline Number of productive stems per $1 \mathrm{~m}^{2}$ & 0.5 & $4,492 *$ & $67,274^{*}$ & 3.9 & 0.217 & 0.18 \\
\hline Number of grains per spike & 0.6 & 22.7 & 148.9* & 2.6 & 0.212 & 0.22 \\
\hline Starch content & 0.4 & $1.9^{*}$ & $23.2^{*}$ & 3.5 & 0.241 & 0.10 \\
\hline Plant height & 0.3 & $206^{*}$ & $1,092 *$ & 2.3 & 0.240 & 0.10 \\
\hline Amylogram height & 4.7 & $48,615^{*}$ & $86,184^{*}$ & 1.3 & 0.198 & 0.62 \\
\hline Winter hardiness & 4.5 & $281.9^{*}$ & $321.9 *$ & 1.1 & 0.210 & 0.49 \\
\hline Aqueous extract viscosity & 3.1 & $4.9^{*}$ & $13.2^{*}$ & 1.6 & 0.240 & 0.49 \\
\hline Weight of 1,000 grains & 1.6 & $12.2^{*}$ & $46.9^{*}$ & 2.0 & 0.243 & 0.54 \\
\hline \multirow{2}{*}{\multicolumn{7}{|c|}{$2012^{5,40}$}} \\
\hline & & & & & & \\
\hline Yielding capacity & 0.1 & 41.7 & $1,331^{*}$ & 5.6 & 0.238 & 0.10 \\
\hline Number of productive stems per $1 \mathrm{~m}^{2}$ & 0.5 & $13,887^{*}$ & $44,926^{*}$ & 1.8 & 0.178 & 0.04 \\
\hline Number of grains per spike & 0.6 & 15.3 & $246.7^{*}$ & 4.0 & 0.233 & 0.05 \\
\hline Starch content & 0.4 & $2.1^{*}$ & $9.5^{*}$ & 2.1 & 0.245 & 0.22 \\
\hline Plant height & 0.3 & $104^{*}$ & $899 *$ & 2.9 & 0.240 & 0.10 \\
\hline Amylogram height & 4.7 & $28,052 *$ & $14,855^{*}$ & 0.7 & 0.178 & 0.61 \\
\hline Winter hardiness & 4.5 & $17.9 *$ & 7.0 & 0.6 & 0.190 & 0.69 \\
\hline Aqueous extract viscosity & 3.1 & $2.7^{*}$ & 1.8 & 0.8 & 0.250 & 0.54 \\
\hline Weight of 1,000 grains & 1.6 & $36.1^{*}$ & $43.4^{*}$ & 1.1 & 0.206 & 0.31 \\
\hline Falling number & 1.4 & $7,282^{*}$ & $7,996^{*}$ & 1.1 & 0.213 & 0.37 \\
\hline $\begin{array}{l}\mathrm{N} \text { o t e: } \mathrm{D}, \mathrm{H}_{1}, \mathrm{H}_{2} \text {, and } \mathrm{h}^{2}-\text { accordin } \\
* \text { Reliable at } 5 \% \text { significance level. }\end{array}$ & B.I. Hayman & & & & & \\
\hline
\end{tabular}

The above division of the studied characters into groups makes it possible to use a differentiated approach to the assessment of their genetic systems and substantiation of methods for improvement by breeding.

The distinctive property of characters from Group 1 was strong depres- 
sion in case of inbreeding, low contribution of additive gene effects to heritability, relatively high (except for starch) hypothetic heterosis in case of interline crossings (34.4-174.6\%), as well as a point where the regression line crosses the $W_{r}$ axis, which is located below the datum point (Fig. 1).

The expression of characters from this group strongly depends on effects of dominance in loci and on interaction of epistatic genes. The significant effect of epistasis was revealed in both years of the studies with regard to yielding capacity, plant height, number of grains per spike and starch content. It is to be supposed that it had a substantial influence on the dominance component, which led to increase in the potential of the nonadditive genetic dispersion reflecting the high SCA variance.

As for two characters from Group 1 (yielding capacity and plant height), the genetic control system turned out to be relatively stable, and coefficients of correlation $(r)$ between the sum $W_{r}+V_{r}$ (covariance + variance) and average value of parent character $X_{p}$ were consistently negative by years, which is indicative of high expression of these characters under control of dominant genes. However, in respect to the number of productive stems per $1 \mathrm{~m}^{2}$ and number of grains per spike, coefficients $r$ for 2011 were unreliable, which gives evidence of genetic system instability due to the influence of weather conditions. A similar peculiarity was also noted for starch content in 2012. It manifested itself as strong genotype-environment interaction when dominant genes had different expressivity due to different lodging resistance of lines. Therefore, with regard to the two mentioned characters, it is reasonable to make a selection assessment of inbred lines through testing in various environmental conditions.

Group 2 turned out to be more numerous than Group 1. It is quite consistent with H.H. Geige's conclusion [5] that, for most of winter rye characters, the additive variance is much greater than the sum of all other components of the genetic variance. The specific feature of characters from this group consists in relatively high contribution of additive genetic effects to character heritability, as well as in weak inbreeding depression and relatively low (except for falling number, amylogram height and aqueous extract viscosity) hypothetic heterosis in case of interline crossings. We did not observe stable effects of epistasis for any of these characters.

A predominant role in their determination is played by additive effects of genes, and it should be noted that dominant genes provided positive increase in almost all grain quality characters, except for protein content (Fig. 2).

In case of six characters from this group (winter hardiness, weight of 1,000 grains, grain unit, falling number, aqueous extract viscosity, protein content), weather conditions had little effect on the genetic control system in the years of the studies. This system turned out to be relatively stable because coefficients of correlation $(r)$ between $W_{r}+V_{r}$ and $X_{p}$ were significant and were consistent in sign by years, i.e. the trend of dominance remained unchanged. However, strong genotype-environment interaction was observed in respect to other six characters (amylogram height, starch gelatinization temperature, H/D ratio, pan bread volume, as well as damage by the snow mold and brown rust). The environmental instability of genetic systems for these characters was indicated by coefficients of correlation $(r)$ between $X_{p}$ and $W_{r}+V_{r}$, which were unreliable in different years, as well as by the genetic parameters and location points of lines on the Hayman's plot, which were substantially different by years. It is indicative of the lability of the mentioned genetic systems under the influence of the limiting environmental factors. We may suppose that genetic information about these characters is implemented in such an interaction with 
A
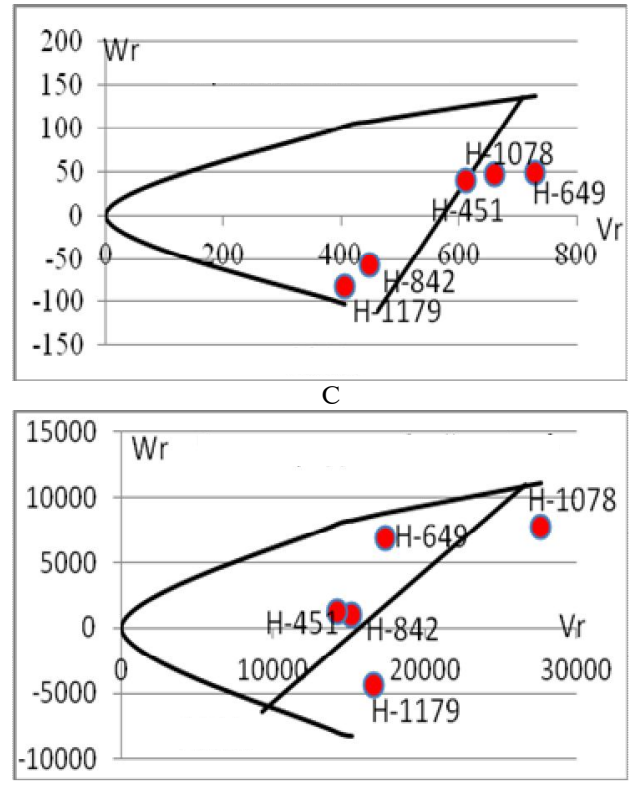

$\mathrm{E}$

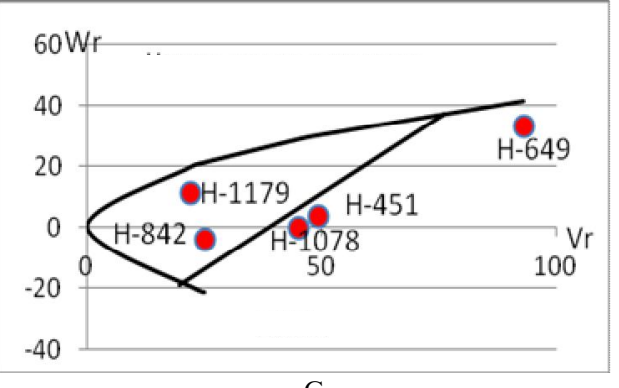

G
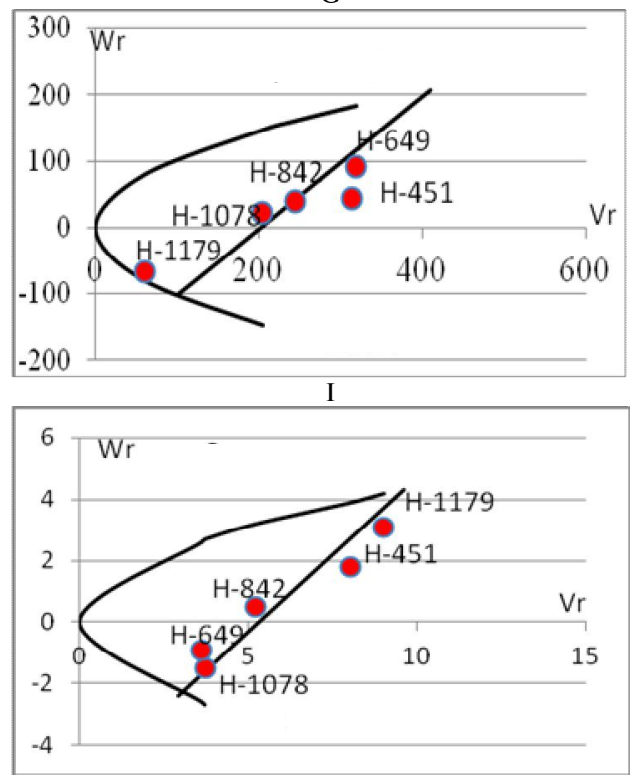

B
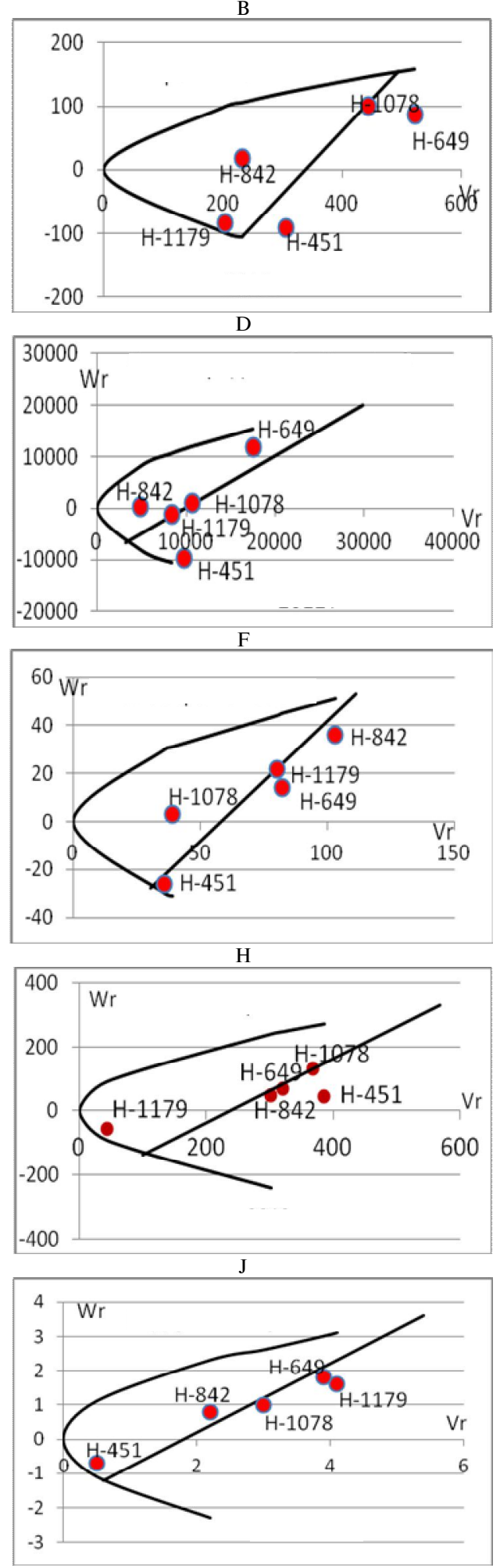

Fig. 1. The plots of regression $W_{I} / V_{T}$ (covariance/variance) for winter rye (Secale cereale L.) lines $\mathrm{H}-649, \mathrm{H}-1078, \mathrm{H}-1179, \mathrm{H}-451$ and $\mathrm{H}-842$ by the characters, for which the variance of general combining ability does not exceed the variance of specific combining ability (Group 1): A, B yielding capacity; C, D - number of productive stems per $1 \mathrm{~m}^{2} ; \mathrm{E}, \mathrm{F}-$ number of grains per spike; G, $\mathrm{H}$ - plant height; I, J - starch content; on the left and right - 2011 and 2012, respectively (Moscow Region). 
A

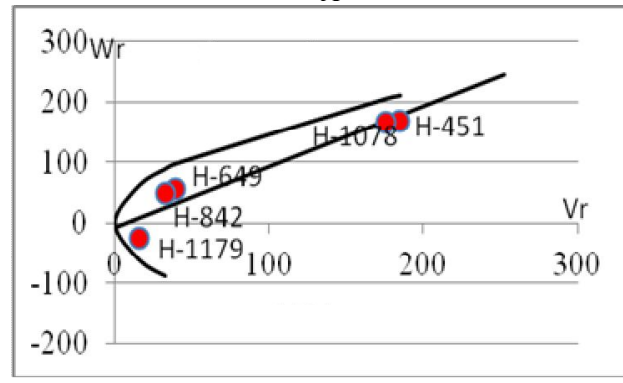

C

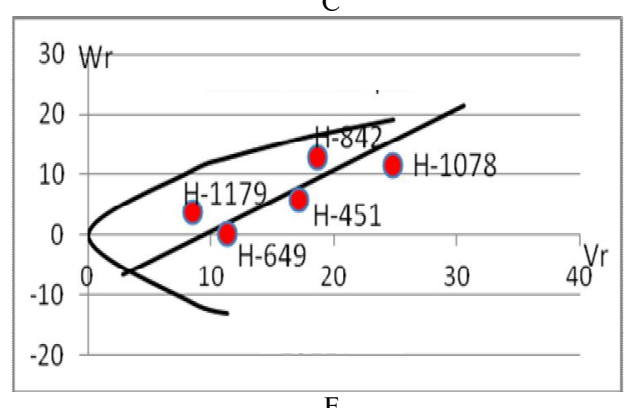

$\mathrm{E}$

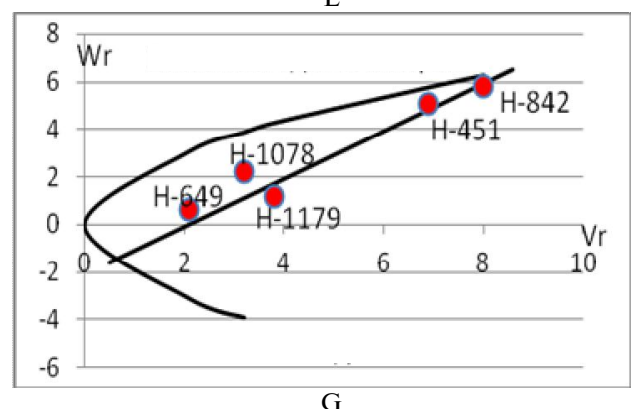

G
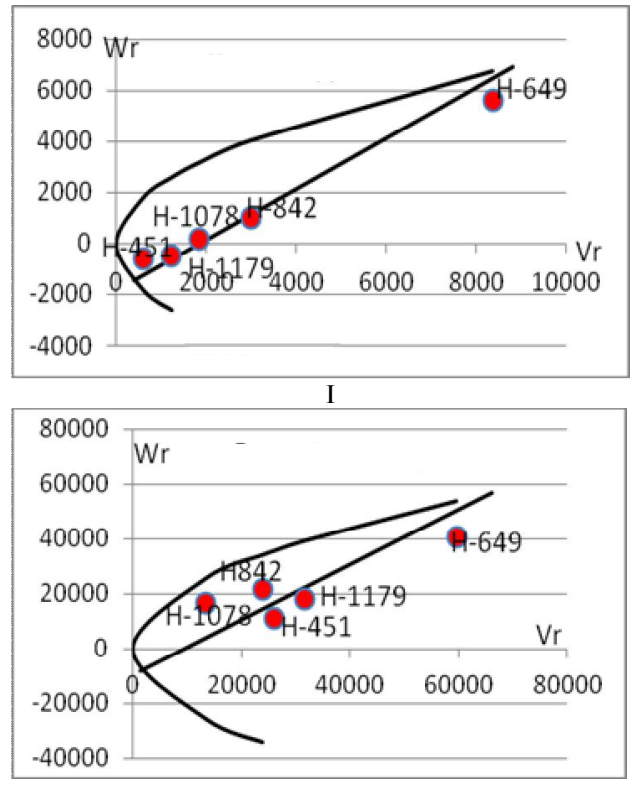

B
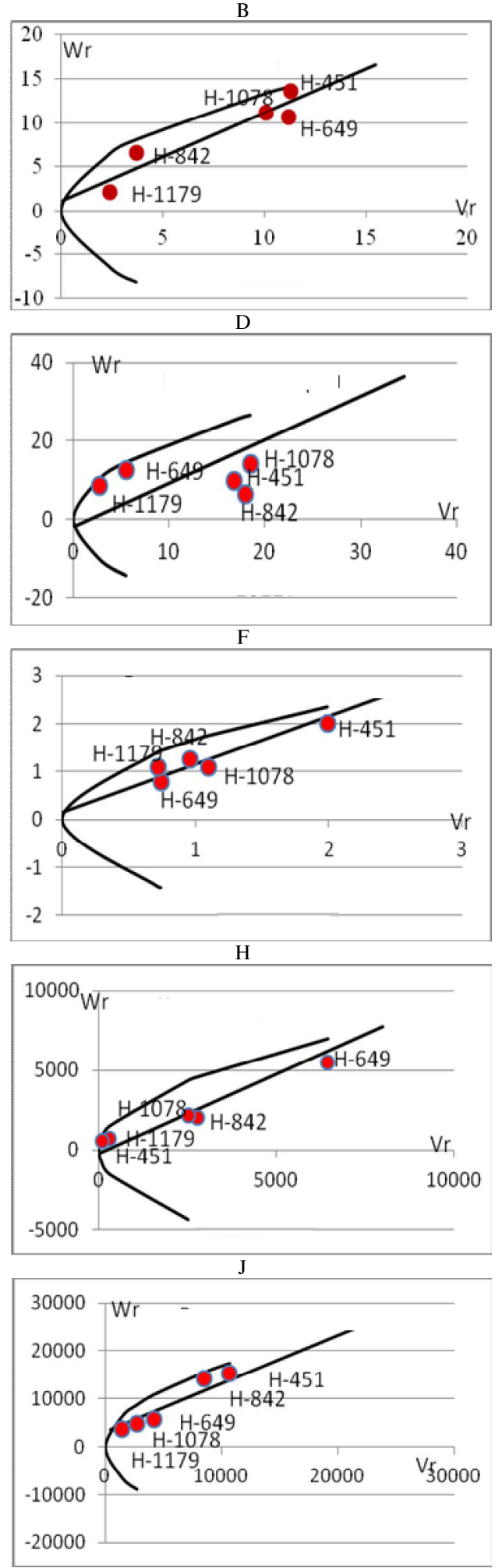

Fig. 2. The plots of regression $W_{t} / V_{r}$ (covariance/variance) for winter rye (Secale cereale L.) lines $\mathrm{H}-649, \mathrm{H}-1078, \mathrm{H}-1179, \mathrm{H}-451$ and $\mathrm{H}-842$ by the characters, for which the variance of general combining ability exceeds the variance of specific combining ability (Group 2): A, B - winter hardiness; C, D - weight of 1,000 grains; E, F-aqueous extract viscosity; G, H - falling number; I, J - amylogram height; on the left and right-2011 and 2012, respectively (Moscow Region). 
the environment when both causes determining it become hardly separable from each other. By this reason, expression of the indicated characters in different years may be determined both by dominant and recessive genes, which complicates the work for their improvement in the course of breeding.

Thus, in order to more efficiently improve low-heritable characters (Group 1), it is necessary to use heterosis breeding methods to the maximum extent possible, and preference shall be given to selection of inbred lines with high Specific Combining Ability (SCA) with regard to yielding capacity and low SCA with regard to plant height. It is reasonable to select inbred lines by highly heritable characters (Group 2) based on the principle of cumulative buildup of valuable genes in them, using the recurrent selection method. It is especially important to adhere to this principle when selecting inbred lines for winter hardiness because the hypothetic heterosis by this character is poorly manifested in interline crossings. The strategy for breeding of lines by the environmentally unstable characters prone to redefining of their genetic formula under the influence of environmental factors (amylogram height, starch gelatinization temperature, dough shape stability, bread volume, damage by diseases) shall be based on early prediction of the general combining ability of parent forms in accordance with the degree of phenotypic expression of such characters in them.

\section{REFEREN C ES}

1. G e ig e r H.H. Hybrid breeding in rye. Proc. of the EUCARPIA Rye Meeting. Svalov, Sweden, 1985: 237-265.

2. Geige r H.H., Mied a n e r T. Rye breeding. In: Handbook Cereals. M.J. Carena (ed.). Springer Science + Business Media, LLC, 2009: 157-182.

3. Karpenstein-Machan M., Maschka R. Progress in rye breeding. Vortr. Pflanzenzuchtung, 1996, 35: 7-13.

4. G e ig e r H.H. Wege, Fortschritte und Aussichten der Hybridzuchtung. In: Pflanzenproduction in Wandel. VCH Verlag, Weinheim, 1990: 41-72.

5. G e ig e r H.H. Breeding methods in diploid rye (Secale cereale L.). Tag.-Ber. Akad. Landwirtsch.-Wiss. DDR, Berlin, 1982, 198: 305-332.

6. Wilde P., Me nze l J., S chmied chen B. Estimation of general and specific combining ability variances and their implications on hybrid rye breeding. Plant Breeding and Seed Science, 2003, 47(1/2): 89-98.

7. G e i g e r H.H. Züchtung. In: Roggen. Anbau - Verarbeitung - Markt. W. Seibel, W. Steller (eds.). Behr's Verlag, Hamburg, 1988: 25-43.

8. Kolasinska I., Wegrzyn S. Combining ability for selected characters in winter rye. Proc. of the EUCARPIA Rye Meeting. Radzikow, Poland, 2001: 91-96.

9. S mi alowski T., Wegrzyn S. The genetic and statistical analysis of the heritability of important traits in winter rye (Secale cereale L.). Biuletyn IHAR, 2003, 230: 205-214.

10. S mialowski T., Wegrzy $\mathrm{S}$. The influence of environments on the epistatic effects of genes controlling some traits in winter rye. Proc. of the EUCARPIA Rye Meeting. Radzikow, Poland, 2001: 105-117.

11. Ge ige r H.H. Epistasis and heterosis. Proc. Second Int. Conf. on Quantitative Genetics (31 May-5 June 1987). B.S. Weir (ed.). Raleigh. NC. Sinauer Assoc. Inc., Sunderland MA, USA, 1987: 395-399.

12. Griffing B. Concept of general and specific combining ability in relation to diallel crossing systems. Austral. J. Biol. Sci., 1956, 9: 463-493.

13. H a y $\mathrm{m}$ a $\mathrm{n}$ B.I. The theory and analysis of diallel crosses. Genetics, 1954, 39: 789-809.

14. Folk o n e r D.S. Vvedenie v genetiku kolichestvennykh priznakov [Introduction to genetics of quantitative traits]. Moscow, 1985.

15. G a ma E.E.G., Halla u e r A.R. Relation between inbred and hybrid traits in maize. Crop Sci., 1977, 17: 703-706. 